\title{
COMUNICAÇÃO
}

\section{REAÇÃO DE GENÓTIPOS DE FEIJÃOAO CRESTAMENTO BACTERIANO COMUM, AVALIADO POR DOIS MÉTODOS DE INOCULAÇÃO}

\author{
Reaction of bean genotypes to the common bacterial blight, evaluated \\ by two inoculation methods
}

\author{
Alciani da Silva', Idalmir dos Santos ${ }^{2}$, Adriana Lucia Balbinot ${ }^{3}$, \\ Gilvani Matei ${ }^{4}$, Paulo Henrique de Oliveira ${ }^{5}$
}

\begin{abstract}
RESUMO
Conhecer a resistência de genótipos de feijão à fitopatógenos é importante para uso em programas de melhoramento genético. Duas técnicas de inoculação bacteriana foram testadas para avaliar a sensibilidade de genótipos de feijão ao crestamento bacteriano comum, causado por Xanthomonas axonopodis pv. phaseoli. Foram inoculados folíolos de 56 genótipos de feijão, utilizando-se das técnicas de agulhas múltiplas e incisão com tesoura, utilizando o isolado XAP 15497. Foi possível classificar 21 genótipos resistentes, 13 moderadamente resistentes, 9 moderadamente suscetíveis e 13 suscetíveis pelo método de inoculação com agulhas múltiplas. No método de inoculação com tesoura, foi possível classificar 24 genótipos como resistentes, 21 como moderadamente resistentes, 7 como moderadamente suscetíveis e 4 suscetíveis. Os genótipos IPR Chopim, IAPAR 81, IAPAR 16, BRS Campeiro, BRS Radiante, IAPAR 80, UTF 6, SM 9906, PI 2072620, LP 01-51, PB 4, Uirapuru, IAPAR 20, Zonin, IAPAR 31, 2 V, CNPF 7762, BRS Talismã, Pérola, Lon Rosinha e UTF 9 tiveram comportamento semelhante diante dos dois métodos de inoculação. Verificou-se que os dois métodos de inoculação foram eficientes para a determinação das reações de suscetibilidade e resistência dos genótipos. Porém, a técnica de inoculação com agulhas múltiplas demonstrou maior praticidade e precisão para a avaliação da área foliar inoculada.
\end{abstract}

Termos para indexação: Resistência, Phaseolus vulgaris, Xanthomonas axonopodis pv. phaseoli.

\section{ABSTRACT}

The knowledge of resistance of bean genotypes to pathogens is important to genetic breeding programs. Two methods of bacterial inoculation were tested to evaluate the sensitivity of bean genotypes to common bacterial blight, caused by Xanthomonas axonopodis pv. phaseoli. Leaves of 56 bean genotypes were inoculated by the method of multiple needles and the method of incision with scissors, using the isolated XAP 15497. We classified 21 genotypes as resistant, 13 as moderately resistant, 9 as moderately susceptible, and 13 as susceptible by the method of inoculation with multiple needles. With the method of inoculation with scissors it was possible to classify 24 genotypes as resistant, 21 as moderately resistant, 7 as moderately susceptible, and 4 as susceptible. The genotypes IPR Chopim, IAPAR 81, IAPAR 16, BRS Campeiro, BRS Radiante, IAPAR 80, UTF 6, SM 9906, PI 2072620, LP 01-51, PB 4, Uirapuru, IAPAR 20, Zonin, IAPAR 31, 2 V, CNPF 7762, BRS Talismã, Pérola, Lon Rosinha, and UTF 9 had similar behavior in the two methods of inoculation. Both methods of inoculation were efficient in determining the reactions of susceptibility and resistance of the genotypes but the method of inoculation with multiple needles was more precise and practical in the evaluation of the inoculated portion of the leaf.

Index terms: Resistance, Phaseolus vulgaris, Xanthomonas axonopodis pv. phaseoli.

(Recebido em 19 de junho de 2008 e aprovado em 25 de novembro de 2008)

As doenças podem ser consideradas como fatores limitantes na produtividade do feijão (Phaseolus vulgaris L.), visto que a cultura é vulnerável a vários organismos fitopatogênicos. Entre as doenças da parte aérea, as bacterianas apresentam grande importância na cultura do feijoeiro, sendo que o crestamento bacteriano comum (CBC), causado por Xanthomonas axonopodis pv. phaseoli (Smith) (=X. campestris pv. phaseoli) (Xap) é considerada a de maior importância (Vieira, 1983; Rava \& Sartorato, 1994). O CBC causa prejuízos na produção em

\footnotetext{
'Engenheira Agrônoma - Cresol - Rua Raul Martins, 237 - 85630-000 - Enéas Marques, PR - alcianisilva@yahoo.com.br ${ }^{2}$ Engenheiro Agrônomo - Professor Doutor em Fitopatologia da UTFPR - Via do Conhecimento - Cx. P. 571 - $85505-970$ - Pato Branco, PR idalmir@utfpr.edu.br

3Engenheira Agrônoma. Bairro Menino Deus - Rua Romilda Aires, 162 - 85502-130 - Pato Branco, PR - adriana balbinot@yahoo.com.br ${ }^{4}$ Engenheiro Agrônomo - Cerealista Ceccon - Rodovia PR 475, Km 57 - Cx. P. 11 - 85585-000 - Verê, PR - gilvanimatei@yahoo.com.br ${ }^{5}$ Engenheiro Agrônomo, Professor Doutor em Melhoramento Genético da UTFPR - Via do Conhecimento - CX. P. 571 - $85505-970$ - Pato Branco, PR phenriqueoliveira@gmail.com
} 
razão da sua ampla distribuição nas regiões produtoras de feijão do Brasil e ao seu difícil controle. Os sintomas aparecem em toda a parte aérea da planta, afetando folhas, caules e sementes (Rava, 1988). Reduções na colheita de 10 a $70 \%$ em condições de ataque natural foram relatadas por Diaz (2000). Isso pode ser explicado em razão da redução da taxa fotossintética das folhas infectadas (Diaz et al., 2001). A bactéria causa ainda imperfeições na semente como descoloração no hilo, manchas amarelas no tegumento e enrugamento (Maringoni et al., 1998). Esses aspectos podem reduzir o valor comercial das sementes.

Uma alta taxa de transmissão de Xap da semente para a planta foi constatada por Valarini et al. (1996), além de verificar que a doença reduz a emergência das plântulas. A importância do CBC tem sido descrita em razão da dificuldade de controle da doença, principalmente para o cultivo em áreas com alto potencial de inóculo e a ineficiência do controle químico, tanto para tratamento de sementes, quanto por meio de pulverizações foliares. Entre as medidas de controle empregadas verifica-se o cultivo em áreas não infestadas com o patógeno, uso de sementes sadias, rotação de culturas, uso adequado de irrigação e o emprego de cultivares resistentes (Maringoni \& Lauretti, 1999). Entre as estratégias do manejo integrado de doenças, a resistência genética é considerada uma importante alternativa, sendo de fácil adoção pelos agricultores em razão de seu baixo custo e por ser ecologicamente segura, diminuindo, ou até mesmo evitando, o uso indiscriminado de defensivos agrícolas (Costa \& Rava, 2003).

Muitas pesquisas foram desenvolvidas visando a conhecer o nível de resistência de variedades de feijoeiro a Xap (Rava, 1984; Opio et al., 1996; Torres \& Maringoni, 1997; Maringoni, 1998; Kobayasti et al., 1999; Maringoni \& Laureti, 1999; Theodoro, 2004). A importância desses trabalhos pode ser ressaltada porque fornecem aos agricultores indicações de variedades adequadas para o plantio em áreas infestadas. Além disso, salienta-se a importância de conhecer o nível de resistência ao CBC de genótipos de feijão que ainda não foram testados e que poderão ser empregados como progenitores de resistência em cruzamento com materiais suscetíveis. Ao mesmo tempo, conhecer a praticidade, rapidez e confiabilidade de um método de inoculação são importantes para a avaliação da reação do feijão. Nesse sentido, conduziu-se este trabalho com o objetivo de avaliar a reação de 56 genótipos de feijão quanto à resistência ao crestamento bacteriano comum causado por Xanthomonas axonopodis pv. phaseoli por meio de inoculação artificial, utilizando-se de dois métodos.
O ensaio foi conduzido em cultivo protegido na Universidade Tecnológica Federal do Paraná (UTFPR), em Pato Branco - PR, com implantação em 14/03/2005. A região situa-se entre as coordenadas de $25^{\circ} 07^{\prime}$ Sul e $52^{\circ} 41^{\prime}$ Oeste e altitude média de $700 \mathrm{~m}$. O clima é classificado como Cfb segundo Köppen e o solo como latossolo vermelho distrófico.

Foram avaliados 56 genótipos de feijão utilizados no Programa de Melhoramento Genético da UTFPR. O padrão de resistência escolhido foi Iapar 16 (Maringoni, 1998). O delineamento experimental empregado foi o inteiramente casualizado, com três repetições. Cada unidade experimental foi representada por uma linha de plantas de um metro de comprimento, espaçadas 30 centímetros, cultivados em estufa.

$\mathrm{O}$ isolado de Xanthomonas axonopodis pv. phaseoli utilizado foi o XAP 15497, fornecido pelo Instituto Agronômico do Paraná (IAPAR), Londrina - PR, o qual foi multiplicado em meio PSA e incubado a $28^{\circ} \mathrm{C}$, por 30 horas. A suspensão bacteriana utilizada para inoculação dos materiais foi de $10^{8}$ ufc. $\mathrm{ml}^{-1}$. A inoculação artificial nas folhas foi realizada utilizando duas técnicas diferentes, 22 dias após a semeadura dos genótipos. Antecedendo a inoculação da bactéria nos genótipos, os aspersores de irrigação foram ativados por 10 minutos a fim de proporcionar o molhamento foliar das plantas. Para a inoculação com agulhas múltiplas, utilizaram-se cinco agulhas cravadas equidistantemente numa rolha de $2 \mathrm{~cm}$ de diâmetro. Posteriormente, o folíolo principal da terceira folha trifoliada de cada planta de feijão a ser inoculada, foi colocado sobre uma esponja umedecida com a suspensão bacteriana, pressionando-se o conjunto de agulhas sobre a folha, baseando-se na metodologia de Andrus (1948). Em seguida, no folíolo lateral da mesma planta, foi realizada a inoculação com tesoura previamente mergulhada na suspensão bacteriana, fazendo cinco cortes de aproximadamente $1 \mathrm{~cm}$ de comprimento ao redor da folha, do bordo para o centro da mesma, baseada na metodologia utilizada por Schoonhoven \& Pastor-Corrales (1987). Após a inoculação e durante o período que se sucedeu à condução do experimento, foi realizado molhamento superficial das folhas por meio de irrigação, por um período de 10 minutos, ao final do dia. A temperatura da estufa oscilou entre $22-28^{\circ} \mathrm{C}$ durante o dia e $18-22^{\circ} \mathrm{C}$ durante a noite, durante o período experimental.

As avaliações foram realizadas 20 dias após a inoculação, por meio da observação da severidade da doença conforme a técnica utilizada. Para o método de agulhas múltiplas, os sintomas foliares foram avaliados por meio da análise da severidade da área foliar inoculada 
adaptada da escala de Maringoni \& Lauretti (1999), enquanto que para a técnica de incisão com tesoura analisou-se a severidade de toda a folha, baseada na escala diagramática de Schoonhoven \& Pastor-Corrales (1987). As médias das severidades das folhas inoculadas foram submetidas ao teste Scott-Knott com 5\% de probabilidade.

$\mathrm{Na}$ Tabela 1, estão apresentadas as médias referentes a reação dos genótipos de feijoeiro a Xanthomonas axonopodis pv. phaseoli. A discriminação dos materiais de acordo com a severidade dos sintomas das plantas revelou a existência de diferenças na reação foliar ao isolado XAP 15497 entre os genótipos avaliados em cultivo protegido diante das duas técnicas de inoculação utilizadas (agulhas múltiplas e tesoura). Para o método de inoculação com agulhas múltiplas, verificouse resistência dos genótipos IPR Chopim, IAPAR 81, IAPAR 16, BRS Campeiro, L 2810423, BRS Radiante, Minuano, IPR Juriti, IAPAR 80, UTF 6, IAPAR 57, SM 9906, PI 2072620, LP 01-51, UTF 10, PB 4, Uirapuru, UTF 7, IAPAR 20, Zonin e IAPAR 31. Com relação ao método de inoculação com tesoura, esse aspecto foi observado nos genótipos L 185633, IAPAR 16, UTF 6, Zonin, PB 4, BRS Campeiro, IPR Chopim, XAN 159, LP 99-79, LP 9323, L 64-5132, LP 01-51, PI 2072620, SCS 202-GUARÁ, IAPAR 81, L 264219, IAPAR 80, LH 11, BRS Radiante, SM 9906, UTF 4, IAPAR 20, Uirapuru e IAPAR 31, os quais apresentaram os menores índices de severidade. É importante destacar que os genótipos BRS Campeiro, BRS Radiante, IAPAR 16, IAPAR 20, IAPAR 31, IAPAR 80, IAPAR 81, IPR Chopim, UTF 6, LP 01-51, PB 4, PI 2072620, SM 9906, Uirapuru, Zonin receberam a mesma classificação diante das duas técnicas de inoculação. Alguns dos resultados obtidos no presente trabalho foram observados por outros autores, utilizando diferentes métodos de inoculação (Rava, 1984; Maringoni et al., 1993; Rava \& Sartorato, 1994; Opio et al., 1996; Maringoni, 1998; Kobayasti et al., 1999).

Diante do método de agulhas múltiplas, os genótipos que se classificaram como moderadamente resistentes foram XAN 159, LP 99-79, 2 V, L 766317, CNPF 7762, LP 93-23, L 185633, UTF 4, Cavalo-Iraí, BRS Talismã, L 64-5132, SCS 202-Guará e L 264219. Já no método de incisão com tesoura foram moderadamente resistentes os genótipos UTF 7, UTF 2, Minuano, L 711535, BRS Talismã, IPR Juriti, BRS Promissora, IAPAR 14, IAPAR 57, Rudá, Expedito, CNPF 7762, UTF 10, 9 V, 2 V, Cfe 33, L 2810423, BRS Valente, Aporé, UTF 3 e IAPAR 65. Apresentaram moderada suscetibilidade os genótipos UTF 2, LH 11, UTF 3, Pérola, Expedito, BRS Valente, IAPAR 65, Aporé e 9 V pelo método de inoculação com agulhas múltiplas. L 766317,
IAC UMA, Pérola, CNFC 8707, UTF 9875, Cfe 62, CavaloIraí, Lon Rosinha, Feijão PH, UTF 9 e L 486321 foram moderadamente suscetíveis no método de inoculação, incisão com tesoura.

Os genótipos de feijão que ficaram classificados como suscetíveis no método das agulhas múltiplas foram Cfe 33, IAC UMA, CNFC 8707, Cfe 62, Lon Rosinha, UTF 9875, BRS Promissora, UTF 9, Rudá, L 711535, L 486321, IAPAR 14 e Feijão PH. Foram suscetíveis no método de inoculação com tesoura Lon Rosinha, Feijão PH, UTF 9 e L 486321.

Algumas avaliações da resistência do feijão a Xap avaliadas por outros autores se assemelham com as observadas no presente trabalho, porém, diferenças do comportamento dos genótipos também foram encontradas. Opio et al. (1996), avaliando o comportamento de 20 genótipos de feijoeiro classificou IAPAR 14 e PI 207262 como resistentes. IAPAR 14 também se destacou quanto à resistência a Xap por outros autores (Maringoni et al., 1993; Rava \& Sartorato, 1994; Torres \& Maringoni, 1999). Por outro lado, Kobayasti et al. (1999) observou que a cultivar IAPAR 14 possui resistência moderada ao patógeno, concordando com a classificação do presente trabalho diante do método de inoculação com tesoura. Essa diferenciação pode ser explicada em razão da variação patogênica entre isolados de Xap. Cafati \& Kimati (1972), citados por Rava (1984), comparando isolados brasileiros e estrangeiros, verificam que os isolados do Brasil foram mais patogênicos do que um isolado do Chile.

Os dois métodos de inoculação utilizados (agulhas múltiplas e incisão com tesoura) foram eficazes para a determinação dos diferentes níveis de resistência e de suscetibilidade dos genótipos de feijoeiro a Xap. Entretanto, os resultados indicam ainda que dos 56 genótipos utilizados no ensaio, 35 não tiveram relação com um ou outro método utilizado, mostrando que existe uma diferenciação entre os métodos e que, portanto, há a necessidade da padronização dos mesmos quando for optar por uma ou outra técnica de inoculação. Comparando os dois métodos, observou-se que o método de inoculação com agulhas múltiplas mostrou maior praticidade e eficiência durante a inoculação, pois é possível ter uma delimitação mais controlada da área foliar inoculada, enquanto que na técnica de incisão com tesoura não é possível ter o controle exato do tamanho dos cortes. Os resultados aqui obtidos para a inoculação com agulhas múltiplas concordam com aqueles obtidos por Torres \& Maringoni (1999), pois esse método de inoculação foi mais prático quando comparado ao de lâmina de barbear dupla. 
Tabela 1 - Reação foliar de genótipos de feijoeiro ao isolado XAP 15497 de Xanthomonas axonopodis pv. phaseoli, em cultivo protegido, expressas em severidade, avaliadas 20 dias após a inoculação.

\begin{tabular}{|c|c|c|}
\hline \multirow[b]{2}{*}{ Genótipos } & \multicolumn{2}{|c|}{ Métodos de inoculação } \\
\hline & Agulhas Múltiplas & Tesoura \\
\hline IPR CHOPIM & $1.00 \mathrm{a}$ & $8.00 \mathrm{a}$ \\
\hline IAPAR 81 & $4.50 \mathrm{a}$ & $10.50 \mathrm{a}$ \\
\hline IAPAR 16 & $5.50 \mathrm{a}$ & $6.00 \mathrm{a}$ \\
\hline BRS CAMPEIRO & $5.50 \mathrm{a}$ & $8.00 \mathrm{a}$ \\
\hline L 2810423 & $6.00 \mathrm{a}$ & $19.00 \mathrm{~b}$ \\
\hline BRS RADIANTE & $6.00 \mathrm{a}$ & $11.00 \mathrm{a}$ \\
\hline MINUANO & $7.50 \mathrm{a}$ & $15.00 \mathrm{~b}$ \\
\hline IPR JURITI & $8.00 \mathrm{a}$ & $15.50 \mathrm{~b}$ \\
\hline IAPAR 80 & $8.50 \mathrm{a}$ & $11.00 \mathrm{a}$ \\
\hline UTF 6 & $9.00 \mathrm{a}$ & $6.00 \mathrm{a}$ \\
\hline IAPAR 57 & $9.00 \mathrm{a}$ & $17.00 \mathrm{~b}$ \\
\hline SM 9906 & $10.50 \mathrm{a}$ & $11.50 \mathrm{a}$ \\
\hline PI 2072620 & $10.50 \mathrm{a}$ & $10.00 \mathrm{a}$ \\
\hline LP 01-51 & $11.00 \mathrm{a}$ & $10.00 \mathrm{a}$ \\
\hline UTF 10 & $11.00 \mathrm{a}$ & $18.50 \mathrm{~b}$ \\
\hline PB 4 & $11.50 \mathrm{a}$ & $7.00 \mathrm{a}$ \\
\hline UIRAPURU & $11.50 \mathrm{a}$ & $13.00 \mathrm{a}$ \\
\hline UTF 7 & $12.00 \mathrm{a}$ & $15.00 \mathrm{~b}$ \\
\hline IAPAR 20 & $12.00 \mathrm{a}$ & $13.00 \mathrm{a}$ \\
\hline ZONIN & $12.50 \mathrm{a}$ & $6.50 \mathrm{a}$ \\
\hline IAPAR 31 & $12.50 \mathrm{a}$ & $13.00 \mathrm{a}$ \\
\hline XAN 159 & $15.00 \mathrm{~b}$ & $8.00 \mathrm{a}$ \\
\hline LP 99-79 & $15.00 \mathrm{~b}$ & $8.00 \mathrm{a}$ \\
\hline $2 \mathrm{~V}$ & $15.50 \mathrm{~b}$ & $18.50 \mathrm{~b}$ \\
\hline L 766317 & $15.50 \mathrm{~b}$ & $25.00 \mathrm{c}$ \\
\hline CNPF 7762 & $16.00 \mathrm{~b}$ & $18.00 \mathrm{~b}$ \\
\hline LP 93-23 & $16.50 \mathrm{~b}$ & $9.00 \mathrm{a}$ \\
\hline L 185633 & $16.00 \mathrm{~b}$ & $5.00 \mathrm{a}$ \\
\hline UTF 4 & $17.50 \mathrm{~b}$ & $12.00 \mathrm{a}$ \\
\hline CAVALO-IRAÍ & $17.50 \mathrm{~b}$ & $25.50 \mathrm{c}$ \\
\hline BRS TALISMÃ & $17.50 \mathrm{~b}$ & $15.00 \mathrm{~b}$ \\
\hline L 64-5132 & $20.00 \mathrm{~b}$ & $9.50 \mathrm{a}$ \\
\hline SCS 202-GUARÁ & $20.00 \mathrm{~b}$ & $10.50 \mathrm{a}$ \\
\hline L 264219 & $20.00 \mathrm{~b}$ & $10.50 \mathrm{a}$ \\
\hline UTF 2 & $22.50 \mathrm{c}$ & $15.00 \mathrm{~b}$ \\
\hline LH 11 & $22.50 \mathrm{c}$ & $11.00 \mathrm{a}$ \\
\hline UTF 3 & $22.50 \mathrm{c}$ & $20.00 \mathrm{~b}$ \\
\hline PÉROLA & $25.00 \mathrm{c}$ & $22.50 \mathrm{c}$ \\
\hline EXPEDITO & $25.00 \mathrm{c}$ & $17.50 \mathrm{~b}$ \\
\hline BRS VALENTE & $25.00 \mathrm{c}$ & $19.00 \mathrm{~b}$ \\
\hline IAPAR 65 & $27.50 \mathrm{c}$ & $20.50 \mathrm{~b}$ \\
\hline APORÉ & $27.50 \mathrm{c}$ & $20.00 \mathrm{~b}$ \\
\hline $9 \mathrm{~V}$ & $27.50 \mathrm{c}$ & $18.50 \mathrm{~b}$ \\
\hline Cfe 33 & $32.50 \mathrm{~d}$ & $18.50 \mathrm{~b}$ \\
\hline IAC UMA & $32.50 \mathrm{~d}$ & $22.50 \mathrm{c}$ \\
\hline
\end{tabular}


Tabela 1 - continuação...

\begin{tabular}{ccc}
\hline CNFC 8707 & $32.50 \mathrm{~d}$ & $22.50 \mathrm{c}$ \\
Cfe 62 & $32.50 \mathrm{~d}$ & $25.00 \mathrm{c}$ \\
LON ROSINHA & $35.00 \mathrm{~d}$ & $31.00 \mathrm{~d}$ \\
UTF 9875 & $40.00 \mathrm{~d}$ & $25.00 \mathrm{c}$ \\
BRS PROMISSORA & $45.00 \mathrm{e}$ & $16.00 \mathrm{~b}$ \\
UTF 9 & $45.00 \mathrm{e}$ & $42.50 \mathrm{e}$ \\
RUDÁ & $47.50 \mathrm{e}$ & $17.50 \mathrm{~b}$ \\
L 711535 & $50.00 \mathrm{e}$ & $15.00 \mathrm{~b}$ \\
L 486321 & $50.00 \mathrm{e}$ & $60.00 \mathrm{f}$ \\
IAPAR 14 & $50.00 \mathrm{e}$ & $16.00 \mathrm{~b}$ \\
FEIJÃO PH & $67.50 \mathrm{f}$ & $42.50 \mathrm{e}$ \\
\hline CV $(\%)$ & 24.1 & 17.8 \\
\hline
\end{tabular}

As médias indicadas pela mesma letra não diferem entre si ao nível 5\% de probabilidade, segundo o teste Scott-Knott.

De modo geral, os resultados do presente trabalho mostraram a importância de se conhecer a reação dos genótipos do Programa de Melhoramento Genético da UTFPR, visto que ainda não se conhecia o comportamento de muitos dos materiais utilizados como fontes de resistência ao CBC em cultivares locais de feijão. Dessa forma, o melhorista pode escolher o melhor material entre a resistência ao CBC, resistência conjunta com outras doenças e as suas características agronômicas, como inserção das vagens inferiores, resistência ao acamamento, produtividade e adaptabilidade. Por ouro lado, conhecer os genótipos suscetíveis é importante, visto que, esses materiais podem ser evitados nos programas de melhoramento. Além disso, a informação do grau de resistência dos genótipos de feijoeiro ao CBC é importante em razão da ineficácia dos tratamentos químicos para as bacterioses e a importância das transmissões da doença para a parte aérea da planta quando presente nas sementes como foi constatado por Valarini et al. (1996). Dessa forma, o uso de sementes sadias e a incorporação de resistência genética às cultivares adaptadas e produtivas surgem como medidas eficientes e econômicas de controle, principalmente nos sistemas de produção prevalecentes no país (Mohan \& Mohan, 1983).

Nas condições em que este trabalho foi realizado podese concluir que foi possível obter informações de um número expressivo de genótipos resistentes ao isolado XAP 15497 de Xanthomonas axonopodis pv. phaseoli, ainda não avaliados até o momento, e de genótipos que poderão ser evitados nos programas de melhoramento genético de cultivares. Além disso, os métodos de inoculação de folíolos por agulhas múltiplas e por incisão com tesoura foram eficientes para a determinação da reação de resistência e de suscetibilidade dos genótipos de feijoeiro a Xap, sendo que o método de agulhas múltiplas mostrou-se o mais prático durante a inoculação.

\section{REFERÊNCIAS BIBLIOGRÁFICAS}

ANDRUS, C.F. A method of testing beans for resistance to bacterial blights. Phythopathology, Oxford, v.38, p.757759,1948

COSTA, J.G.C.; RAVA, C.A. Linhagens de feijoeiro comum com fenótipos agronômicos favoráveis e resistência ao crestamento bacteriano comum e antracnose. Ciência e Agrotecnologia, Lavras, v.27, n.5, p.1176-1182, set./out. 2003.

DIAZ, C.G. Avaliação de danos causados por Xanthomonas axonopodis pv.phaseoli em feijoeiro (Phaseolus vulgaris L.). 2000. Tese (Doutorado)-Escola Superior de Agricultura Luiz de Queiroz, Universidade de São Paulo, Piracicaba, 2000.

DIAZ, C.G.; BASSANEZI, R.B.; GODOY, C.V.; LOPES, D.B.; BERGAMIN FILHO, A. Quantificação do efeito do crestamento bacteriano comum na eficiência fotossintética e na produção do feijoeiro. Fitopatologia Brasileira, Brasília, v.26, n.1, p.71-76, 2001.

KOBAYASTI, L.; SOUZA, R.M. de; SANTOS, J.B. dos. Avaliação de cultivares e linhagens de feijoeiro quanto à reação foliar e de vagens à Xanthomonas axonopodis pv. phaseoli var. fuscans. Ciência e Agrotecnologia, Lavras, v.23, n.1, p.40-47, jan./fev. 1999.

MARINGONI, A.C. Virulência de isolados de Xanhomonas campestris pv. phaseoli (Smith) Dye em feijoeiro. Pesquisa Agropecuária Brasileira, Brasília, v.33, n.6, p.861-867, 1998. 
MARINGONI, A.C.; FREGONSE, L.H.; TOFOLI, J.G.; KUROZAWA, C. Reação foliar e da vagem de feijoeiro a Xanthomonas campestris pv. phaseoli e transmissão da bactéria pelas sementes. Fitopatologia Brasileira, Brasília, v.18, p.412-415, 1993.

MARINGONI, A.C.; KIMATI, H.; KUROZAWA, C. Comparação de dois métodos de extração de Xanthomonas campestris pv. phaseoli. Pesquisa Agropecuária Brasileira, Brasília, v.33, n.5, p.659-664, 1998.

MARINGONI, A.C.; LAURETTI, R.L.B. Reação de genótipos de feijoeiro comum a Fusarium oxysporum $\mathrm{f}$. sp. phaseoli, Macrophomina phaseolina e Xanthomonas campestris pv. phaseoli. Pesquisa Agropecuária Brasileira, Brasília, v.34, n.4, p.535-532, abr. 1999.

MOHAN, S.T.; MOHAN, S.K. Novas linhagens do feijoeiro resistentes ao crestamento bacteriano comum. Pesquisa Agropecuária Brasileira, Brasília, v.18, n.10, p.1117-1120, out. 1983.

OPIO, A.F.; ALLEN, D.J.; TERI, J.M. Pathogenic variation in Xanthomonas campestris pv. phaseoli, the causal agent of common bacterial bligth in Phaseolus beans. Plant Pathology, v.45, p.1126-1133, 1996.

RAVA, C.A. Patogenicidade de isolamentos de Xanthomonas campestris pv. phaseoli. Pesquisa Agropecuária Brasileira, Brasília, v.19, n.4, p.445-448, abr. 1984

RAVA, C.A. Crestamento bacteriano comum. In: ZIMMERMANN, M.J.O.; ROCHA, M.; YAMADA, T. Cultura do feijoeiro: fatores que afetam a produtividade.
Piracicaba: Associação Brasileira para a Potassa e o Fosfato, 1988. p.527-541.

RAVA, C.A.; SARTORATO, A. Crestamento bacteriano comum. In: Principais doenças do feijoeiro comum e seu controle. Brasília, DF: Embrapa, 1994. p.217-242.

SCHOONHOVEN, V.; PASTOR-CORRALES, M.A. Sistema estándar para La evaluación de germoplasma de frijol. Colombia: Centro Internacional de Agricultura Tropical, 1987. 86p.

THEODORO, G.F. Reação de cultivares locais de feijão a Xanthomonas axonopodis pv. phaseoli, em condições de campo. Revista Brasileira Agrociência, Pelotas, v.10, n.3, p.373-375, jul./set. 2004.

TORRES, J.P.; MARINGONI, A.C. Reação foliar de genótipos de feijoeiro a Xanthomonas campestris pv. phaseoli e transmissão via sementes. Fitopatologia Brasileira, Brasília, v.22, n.4, p.546-548, 1997.

TORRES, J.P.; MARINGONI, A.C. Métodos de inoculação, estádios de desenvolvimento fenológico da planta e reação de cultivares de feijoeiro a Xanthomonas axonopodis pv. phaseoli. Ciência e Agrotecnologia, Lavras, v.23, n.1, p.124-129, jan./mar. 1999.

VALARINI, P.J.; GALVÃO, J.A.H.; OLIVEIRA, D. de A. Xanthomonas campestris pv. phaseoli: importância do inóculo da semente na epidemiologia do crestamento bacteriano comum do feijoeiro. Fitopatologia Brasileira, Brasília, v.21, n.2, p.261-267, jun. 1996.

VIEIRA, C. Doenças e pragas do feijoeiro. Viçosa, MG UFV, 1983. 